\title{
Sintesis evolutiva de la ginecología en los últimos veinte años
}

Discurso pronunciado por el Profesor Héctor Enrique Bernal, Presidente de la Sociedad Colombiana de Obstetricia y Ginecología, para inaugurar las sesiones en la zona Tocoginecológica del VI Congreso Médico Nacional.

Bogotá, julio de 1959.

\section{Distinguidos colegas:}

En nombre de la Sociedad Colombiana de Obstetricia y Ginecología, presento a ustedes un efusivo saludo y una cordial bienvenida.

Para la Sociedad que tengo el honor de presidir, constituye un motivo de suma complacencia el haber colaborado en la organización de éstas jornadas científicas, en donde vamos a hacer el balance de nuestra labor en más de veinte años de Medicina Nacional.

La medicina, al igual que todas las ciencias, no ha podido sustraerse al vertiginoso avance científico de los últimos tiempos; para quienes nos iniciamos en el conocimiento de la patología genital femenina, hace precisamente veinte años, resulta satisfactorio, por decir lo menos, el camino recorrido: evidentemente hemos progresado; pero al mismo tiempo tenemos que aceptar la realidad de que en muchos aspectos nos hemos quedado estacionarios.

Retrocedamos a lo que eran nuestros conocimientos en ese $\epsilon$ tonces. La fisiología de la mujer se enriquecía con los sucesivos hallazgos, y la síntesis de las hormonas que llegaron a considerarse como base de la femineidad. En la hipófisis se utilizaban los extractos del lóbulo posterior y, por experimentos en animales, se intuyeron y se aislaron luego las hormonas gonadotropas del lóbulo anterior. Era la época del auge de la endocrinología, en que 
todo se pretendía explicar por mecanismos exclusivamente humorales. Vinieron luégo el descubrimiento de compuesto químicos de acción similar a las hormonas naturales y activos por vía oral; la terapia hormonal cruzada, ayer un absurdo, hoy un hecho corriente, complementada luégo, por las asociaciones de hormonas que suman sus efectos sinérgicos y sacan partido de sus propiedades antagónicas, el uso y el abuso de las gonadotropinas coriónicas que no correspondieron a las esperanzas que en ellas se había depositado; la separación de los principios ocitócico, y vasopresor y antidiurético en los extractos del lóbulo posterior hipofisiario, etc. Pero en donde la fisiología dio un verdadero vuelco, fue en el cambio del concepto exclusivamente humoral por el más armónico principio del mecanismo neurohormonal, que establece la relación entre los trastornos periféricos del aparato genital y las intimas alteraciones de la vida afectiva.

Entrando en el terreno de la patología, un gran progreso se ha notado en el diagnóstico y tratamiento de los sinđromes funcionales: mediante pruebas sencillas nos es posible saber cómo funcionan los distintos elementos del sistema neuro-endocrinosexual, y también, mediante una terapéutica al alcance de todos, podemos normalizar le ciclo o modificarlo a voluntad, o frenar una hemorragia para la cual antes era indispensable un raspado. A éste progreso han contribuído modernos métodos auxiliares cie diagnóstico, entre nosotros relativamente recientes; la biopsia endometrial, la curva de temperatura basal, el estudio del moco cervical, el urocitograma, la citología vaginal, la dosificación de ios 17 cetoesteroides, etc., para no mencionar sino unos pocos son auxiliares indispensables al ginecólogo de nuestros días; con todo, el camino es aún largo, ya que no podemos conocer con seguridad la cantidad de hormonas circulantes en los diferentes momentos del ciclo, en razon de que los métodos empleados para dichas determinaciones no son lo suficientemente exactos, económicos y simples, como para poder utilizarlos en la clínica corriente.

En el terreno de las infecciones, cuánto camino hemos ganac̆o; si por un momento se llegó a pensar, que ellas quedarían definitivamente erradicadas y tan sólo se mencionarían en los textos a título histórico; el advenimiento, primero de las sulfas y luego, el descubrimiento y la síntesis de poderosos antibióticos, comenzaron a obrar verdaderos milagros; sinembargo, ésta preciosa conquista, está en peligro de perderse, ya sea porque los 
agentes infecciosos han adaptado su biología a las nuevas substancias o porque, tánto se abusa de ellas tan indiscriminadamente, que han perdido una gran parte de su eficacia. Lo cierto es que los ginecólogos contemplamos alarmados el resurgimiento, en éstos últimos tiempos, de infecciones generalizadas de la pelvis que ya parecian extinguidas y la cirugía intenta volver por caminos que le estaban vedados.

Excepción, o mejor conquista de las más importantes, es la ce la enfermedad tuberculosa que tan caro tributo pagaba a la cirugía; hoy la última está casi totalmente relegada y entusiasmados asistimos a la recuperación de funciones consideradas antes perdidas.

No podríamos participar del mismo entusiasmo en cuanto a las infecciones por debajo del orificio externo del cuello, porque si bien es cierto que el gonococo está vencido y que disponemos de agentes específicos contra la enfermedad de Ducrey y el linfogranuloma venéreo, no sucede lo mismo con la infección tricomoniásica, ni con los hongos que por el contrario, al favor de los antibióticos, parecen haber ampliado su campo de acción. ias leucorreas constituirán aun por cierto tiempo el dolor de cabeza de los ginecólogos.

Si a ésta reunión hubiésemos sido convocados hace 25 años, seguramente nos hubieran sonado exóticos algunos términos como endometriosis, sindromes de Meigs, de Turner, de Stein-Leventhal, ciertos tipos de tumores del ovario, etc. En realidad se trata de entidades conocidas de tiempo atrás en otros medios, pero cuya protocolización entre nosotros es relativamente reciente. Una de ellas, la primera, ha despertado grande interés y su estudio constituye uno de los temas oficiales en este grupo.

Materia de extenso capítulo sería tratar de revisar la evolución de la cirugía ginecológica en el lapso que nos ocupa; sin mencionar apenas, desde un punto de vista general, las enormes conquistas que significan la perfecta anestesia, la transfusión segura, la ayuda de una buena instrumentadora, el uso racional die los antibióticos y agentes quimioterápicos, la restauración apropiada de fluídos y electrolitos, etc., podríamos sintetizar ese progreso en dos términos evidentemente antagónicos: cirugía conservadora o funcional y cirugía radical. Ningún elogio es suficiente para ponderar el resultado que se consigue al conservar una función y más cuando esa función entraña por sí misma la base de la femineidad; cuán infinitamente agradecida nos queda la pa- 
ciente a quien, después de la operación, se le informa que se extirpó su lesión pero que conserva su matriz y sus ovarios, pero, si a más de ello, hemos contribuído a perfeccionar una materridad hasta entonces frustrada su agradecimiento llega hasta el delirio: la cirugía funcional está en pie y el espectro de la castración desaparece ante ella. De otra parte, y en el extremo opuesto, se debate la cirugía radical, consuelo único para quien todo lo considera perdido; alabada por unos, criticada por otros, en permanente pugna con la fisioterapia, que le disputa sus casos, constituye de todas maneras un avance, talvez trancitorio, en la lucha contra la malignidad.

Entre éstos dos términos la cirugía restauradora, por su parte, no se ha quedado atrás; los modernos conceptos sobre estática ce los órganos pelvianos y sobre fisiopatología de las distopias permitieron un tratamiento racional de los prolapsos, sin necesidad de acudir a las histerectomías cuando se trata de mujeres jóvenes y sin cegar las vías naturales en mujeres de mayor edad; pero cuando, en éstas últimas, nos vemos abocados a la histerectomía como tratamiento de elección ya no nos limitamos a extirpar un órgano herniado sino que damos mayor importancia a la correcta reposición de los órganos restantes.

En un terreno que podríamos llamar de cirugía gineco-urológica, se corrigen las incontingencias urinarias de esfuerzo, se cierran las fístulas, se canalizan y reimplantan los uréteres, pero, sobre todo, se ha llegado hasta la creación de órganos nuevos como la neo-vejiga, a expensas de las ampollas cecal o rectal. Al lado de ésta cirugía que restaura lesiones adquiridas no podríamos dejar de mencionar la cirugía que repara defectos congénitos del organismo: resulta en verdad sorprendente la facilidad con que hoy creamos una neo-vagina en contraste con las dispendiosas operaciones de otros tiempos.

Si hasta ahora hemos registrado con entusiasmo los avances logrados en diferentes aspectos de la especialidad ginecológica, durante un cuarto de siglo, no podríamos decir lo mismo en cuanto se refiere a la malignidad; a pesar del empleo de isótopos y sales radioactivas, a pesar de las poderosas radiaciones emitidas por los modernos aparatos de Roëtgenoterapia, el cáncer del ovario, de la trompa, de la vulva continúan siendo tributarios de la cirugía, "bien porque sea indispensable como tiempo diagnóstico en los tumores intraabdominales, bien porque, como en el cáncer vulvar, represente el único medio eficaz de tratamiento". De 
todas maneras, a propósito de éste último, es justo consignar que la vulvectomía radical, de reciente introducción en nuestro medio, representa un positivo avance. En cuanto al cáncer uterino se refiere, si el progreso ha sido muy grande en el diagnóstico, debido principalmente al descubrimiento de Papanicolaou, la vieja pugna entre la cirugía radical, para los primeros estados evolutivos, y la fisioterapia continúa al parecer con ventaja para ésta última. Constituye éste, un capítulo tan apacionante que su revisión ha sido incorporada entre los temas de éste Congreso.

Por un descuido inesplicable de los ginecólogos, la patología mamaria que, por definición, pertenece al gran capítulo de la patología femenina, ha sido explotada por cirujanos y endocrinólogos; tan solo de unos años a èsta parte, se ha iniciado el movimiento para reivindicarla a su justo lugar y así vimos con satisfacción su incorporación como tema oficial de la última Convención de la especialidad y la aparición de recientes trabajos sobre el tema.

No podríamos decir lo mimo en cuanto se refiere al estudio y tratamiento de la esterilidad matrimonial, indiscutiblemente ligado, desde siempre, a la práctica del ginecólogo; sin embargo Es tan solo en los dos últimos lustros cuando se ha dado entre rosotros la importancia que merece; es verdad que desde antes se conocían sus principios y se estaba al tanto de sus adelantos: se practicaban histerosalpingografías, insuflaciones con aparatos primitivos, operaciones plásticas, etc., pero su estudio se hacía sin normas fijas y la fórmula de la fertilidad parecía reducida a dos términos: varón potente y trompas permeables. Hoy, podemos decirlo con satisfacción, el estudio de la pareja estéril se hace en consultorios especializados y el trabajo se realiza en equipo con a colaboración indispensable del urólogo, del patólogo, del endocrinólogo, del laboratorista clínico, etc. La labor de educar al público es dura, pero ya comienza a dar sus frutos y no es raro ver acudir al consultorio al marido, despojado del erróneo concepto de que "potencialidad es sinónimo de fertilidad".

Mencionábamos al principio la trascendencia que para la fisiología genital femenina significó el cambio del concepto del "estimulo exclusivamente humoral" por el más armónico principio de la "regulación neuro- hormonal"; si ahora volvemos sobre ello, es para resaltar la importancia de un nuevo capítulo no registrado antes en los tratados de la especialidad: nos referimos a la Ginecología sicosomática, cuyas proyeccines en el futuro son incalculables. De todas maneras conviene saber, que es no solo en 
las alteraciones anatómicas, ni en los trastornos de funcionamiento en donde vamos a encontrar la causa de la enfermedad, sino que debemos penetrar más hondo en la personalidad de la. paciente y darnos cuenta de sus conflictos sociales y económicos, de sus sentimientos y sus ansiedades, en una palabra, de su vida efectiva.

Conducidos por las disciplinas que nos son más propias hemos paseado rápidamente por los campos de la Ginecología sin detenernos en el panorama de la moderna Obstetricia, y ya es tarde para hacerlo; abusaría de la paciencia de ustedes si tal intentara, pero ello no obsta para señalar, siquiera en lontananza, hechos tan grandes como las pruebas biológicas en los animales de sangre fría, en el diagnóstico precoz del embarazo, la investigación del factor $\mathrm{RH}$, el síndrome de deplesión de sodio, el progreso en el estudio de las toxemias, la fibrinogenopenia como causa de hemorragia fatal en el post-parto, la analgesia obstétrica, la inducción electiva del parto y, sobre todo, el método sicoprofiláctico para "transformar el dolor en alegría". Algunos de éstos temas serán tratados aquí por quienes tienen autoridad pada hacerlo.

\section{Señores delegados:}

Al declarar formalmente inauguradas las sesiones de grupoen la rama Obstétrico-ginecológica del Sexto Congreso Médico Nacional, hago votos porque las semillas que aquí se siembren produzcan hermosos frutos para bien de Colombia. 